\section{Yucca sex}

SIR - As Peter Moore reported in News and Views ${ }^{1}$, there is indeed a "fly in the ointment" of the relationship between $Y u c c a$ and its pollinator, and it is definitely a Dipteran. The close interdependence between the Yucca and its moth may involve a "balance of self-interests" as Moore notes, but there is plenty of opportunity for unbalanced positions. Large populations of moths may tilt the scales to one side and reduce or eliminate $Y$ ucca seed production. The unpredictable timing of viable fruit development may reduce such effects of moth overabundance $^{2}$. The scales will assuredly tilt the other way if moths are few, Yucca flowers many and pollination service is inadequate.

Such events are common in those portions of the Yucca geographical range where late and unpredictably cold springs decrease moth populations to low levels. Under these conditions, the fly Pseudocalliope sp. nov. (Lauxaniidae, Diptera) can be an important pollinator ${ }^{3}$. These flies exist in large numbers within flowers, where they court and mate. They carry Yucca pollen on their bristly bodies, from anthers to stigma both within and among flowers. The Yucca populations where this fly is found are also self-compatible, and can be pollinated via pollen deposition on the stigma (rather than requiring elaborate pollen-tamping behaviour by the moths into a stigmatic crevice as is often described ${ }^{4}$ ). In these populations, hand pollination can also increase seed set, in contrast to the populations described in ref. 2. The high densities and abundant reproduction of Yucca populations in these regions attest to the long-term effectiveness of this alternative solution.

These results indicate that Yucca "selfinterests" are well served by keeping a flexible breeding system receptive to variable ecological settings, rather than depending on the conventions about the perfection of mutualisms.

Yan B. Linhart

Rhea J. Dodd

Department of Environmental,

Population and Organismal Biology,

University of Colorado,

Campus Box 334

Boulder, Colorado 80309, USA

SIR - Moore in a News and Views article ${ }^{1}$ compared how yuccas and figs control seed consumption by their pollinators. We would like to point out that several recent studies show that there is little or no empirical support for many of the mechanisms that have commonly been proposed to allow figs to avoid overexploitation by their pollinator/seeds predators.
First, in many cases, the foundress wasps which pollinate the figs carry more than enough eggs to saturate all of the female flowers ${ }^{5}$. Second, style length within figs is distributed unimodally and not into short- and long-styled classes and the ovipositors of wasps are long enough to oviposit in a much larger proportion of flowers than actually develop into wasps ${ }^{6}$. Third, in many fig species the ostioles (the pore through which fig wasps gain entrance to the flowers) are simple structures that do not filter non-adapted pollinator species, nor do they prevent certain nonpollinating wasp species from entering the figs, laying their eggs, and then leaving ${ }^{7}$. Finally, most fig trees do not produce crops of fruit simply to maintain the wasps, the only documented example being Ficus carica (the edible fig) ${ }^{8}$. Overall, researchers' perceptions of the figwasp mutualism changed drastically as a result of studies done in the mid-1980s.

We hope that this shift, and its bearing on the more general understanding of mutualism, will soon be more widely appreciated.

\section{F. Kellberg}

M.-C. Anstett

CNRS-CEFE, BP 5051

34033Montpellier,

France

E. A. Herre

Smithsonian Tropical

Research Institute,

POBOx 2072,

Balboa,

Panama

1. Moore, P. D. Nature 368, 588-589 (1994)

2. James, C. D.etai. Oikos $69,207-216$ (1994).

3. Dodd. R. J. \& Linhart, Y. B. Am. J. Bot. 81, 815-825 (1994)

4. James, C. D. et al. Oecologia 98, 512-517 (1993).

5. Herre, E. A. Experientia 45, 637-647 (1989).

6. Bronstein. J. L. Ecology 69, 1298-1302 (1988).

7. Ware, A. B. \& Compton, S. G. Biotropica 24, 544-549 (1992).

8. Kjellberg, F., Gouyon, P. H., Ibrahim, M., Raymond, M. \& Valdeyron, G. Evolution 41, $693-704$ (1987).

\section{Painted out}

SIR - Lister's evocative phrase in News and Views ${ }^{1}$ that mammoths survived to co-exist with the Egyptian pharaohs led Rosen to suggest that an individual dwarf mammoth appears in a scene in a wall painting in a pharaonic tomb $b^{2}$. Unfortunately, there are several objections to this intriguing view.

In the tomb concerned (that of Rekhmire in the XVIIIth Dynasty), the painted scenes were executed in around $1430 \mathrm{BC}$ and, therefore, are younger than the lowest radiocarbon ages quoted for the dwarf mammoths of Wrangel Island in the Arctic Ocean ${ }^{3}$. The northeast Siberian specimens mentioned represented a dwarf form of the woolly mammoth, Mammuthus primigenius (Blumenbach); although Rosen regards some elements in the creature illustrated as being suggestive of mammoth, certain diagnostic features (fatty hump, long pelt, small ears and distinctive tusks, curved in two planes) known for the type specimen of $M$. primigenius $^{4,5}$ are entirely lacking.

Mention has been made that the bear in the painted scene would have been as exotic as a dwarf mammoth to the artist, but this applies equally to the elephant, for it was not native to Egypt in pharaonic times. Although the position of the tusks of the animal depicted is claimed as characteristic of a mammoth rather than of the African elephant, Loxodonta africanus, the upward-pointing tusks occur in stylized portraits of elephants whenever the latter appear in Egyptian art (and indeed in hieroglyphic writing, where the word for elephant, $a b w$, includes an ideogram showing an elephant with upwardprojecting tusks) ${ }^{6}$. Finally, although Rosen concedes that transport of live animals from central Africa to ancient Egypt has not been documented, he appears unworried that this also applies to the Arctic (after all, the bear accompanying the elephant in the tomb's tribute scene is not a polar bear).

Attractive though Rosen's theory may be, there is no reason to suppose that the Egyptian artist intended to depict anything other than an African elephant, the differential scaling of the human and animal figures being the result of stylistic convention rather than the naturalistic representation of extreme dwarfism. Similar intentional size disparities between human figures of different social rank are to be seen in Egyptian art and, indeed, within the same tomb.

\section{William White}

61 Eskdale Avenue,

Chesham,

Buckinghamshire HP5 3 AY, UK

1. Lister, A. M. Nature 362, 288-289 (1993).

2. Rosen, B Nature 369, 364 (1994)

3. Vartanyan, S. L., Garutt, V. E. \& Sher, A. V. Nature 362, 337-340 (1993)

4. Garutt, V. E., Gentry, A. \& Lister, A. M. Bull. zool. Nomencl. 47, 38-44 (1990).

5. Guthrie, R. D. Frozen Fauna of the Mammoth Steppe: the Story of Blue Babe (Univ. Chicago Press, 1990).

6. Gardiner, A. Egyptian Grammar 3rd edn (Oxford Univ. Press, UK, 1957)

\section{Scientific Correspondence}

Scientific Correspondence is a relatively informal section of Nature in which matters of general scientific interest, not necessarily those arising from papers appearing in Nature, are published. Because there is space to print only a small proportion of the letters received, priority is usually given according to general interest and topicality, to contributions of fewer than 500 words, and to contributions using simple language. 